\title{
FOUCAULT Y LOS ORÍGENES GRIEGOS DE LA BIOPOLÍTICA ${ }^{1}$
}

\author{
Rodrigo Frías Urrea \\ Centro de Estudios Clásicos \\ Universidad Metropolitana de Ciencias de la Educación \\ rodrigo.frias@umce.com
}

\begin{abstract}
Resumen / Abstract
En el presente artículo sometemos a examen la definición de biopolítica ofrecida por Foucault; en especial en lo que se refiere al problema de sus orígenes. Foucault, en efecto, defiende la tesis según la cual la moderna biopolítica tendría su origen más remoto en la arcaica pastoral cristiana; en nuestra opinión, en cambio, habría buenas razones para pensar que ese origen se encontraría en Platón, en el sentido de que en él habría habido, al menos, una orientación biopolítica del pensamiento.
\end{abstract}

Palabras Clave: Foucault, Platón, biopolítica, pastoral cristiana.

\section{FOUCAULT AND THE GREEK ORIGIN OF BIOPOLITICS}

The following article examines Foucault's definition of biopolitics, especially the problem of its origin. Foucault's thesis is that modern biopolitics has its most remote origin in the ancient Christian pastoral work; however, there are good reasons to believe that the origin may be found in Plato, given the biopolitical direction of his thought.

KEY WORDS: Foucault, Plato, biopolitics, Christian pastoral work.

\section{Biopolítica como 'gobierno de los hombres'}

R⿴囗十

Según la ampliamente difundida interpretación de Heidegger sobre la esencia de la técnica moderna, nuestra época correspondería a la de la 'imagen del mundo' precisamente porque en ella la 'totalidad de lo vivo' ha sido llevada a la condición de lo 'puesto' para su uso y aprovechamiento; al punto que la naturaleza aparecería ante todo como una 'gigantesca estación de servicio' y el hombre como simple 'recurso humano'. Para Heidegger mismo, sin embargo, este moderno fenómeno del imperar

Este artículo forma parte del proyecto de investigación "Platón y los orígenes griegos de la biopolítica" (FIBE 03-12), financiado por la Dirección de Investigación de la Universidad Metropolitana de Ciencias de la Educación. 
de la esencia de la técnica, y la racionalidad calculante que le es propia, tiene ante todo un carácter ontológico, pues con él se describiría el último estadio de la historia de la metafísica como historia del nihilismo (cf. Heidegger 2000, pp. 259-297). Otros, en cambio, han visto en este 'ingreso de la vida en la lógica del cálculo' un fenómeno primariamente histórico-político, con una cronología bastante precisa. Es el caso de H. Arendt (2005), H. Jonas (2008) y, sobre todo, Michel Foucault, a quien debemos no solo el más conocido tratamiento de este fenómeno sino, sobre todo, la reacuñación misma de la expresión con el que se conoce, en la que justamente se conjugan bios y política: para Foucault, en efecto, la época moderna es la época de la biopolítica (vid. Esposito 2004).

Biopolítica, de hecho, es una expresión usada por Foucault para describir aquella "forma en que, a partir del siglo XVIII, se han intentado racionalizar los problemas que planteaban a la práctica gubernamental fenómenos propios de un conjunto de seres vivos constituidos como población" (Foucault 1999, p. 209). Ya antes de este texto, sin embargo, Foucault había reintroducido en el lenguaje filosófico la expresión 'biopolítica'; concretamente en la conferencia Las mallas del poder, del año 1976, en la que ensaya un análisis de la noción de poder libre de la comprensión estrechamente jurídica-represiva de la ley; y donde divide en dos las invenciones de la tecnología política (con énfasis en los siglos XVII-XVIII): "Por un lado, dice Foucault, existe esa tecnología que llamaría «disciplina». La disciplina es, en el fondo, el mecanismo de poder por el cual llegamos a controlar en el cuerpo social hasta los elementos más tenues, y por éstos alcanzamos los átomos sociales mismos, es decir, los individuos [...] a grandes rasgos, una especie de anatomía política, de anatomopolítica”. Y por otro, existe otra tecnología política, de invención algo posterior, que no se dirige a los individuos aisladamente sino a las poblaciones humanas. En efecto, afirma el autor, paralelamente a la aparición de la anatomopolítica "se descubre que sobre lo que se ejerce el poder es sobre la población, que no quiere decir simplemente un grupo humano numeroso, sino seres vivos atravesados, mandados y regidos por procesos y leyes biológicas [...] En este momento se inventó [...] la biopolítica". En resumen, "en la tecnología del poder han tenido lugar dos grandes revoluciones: el descubrimiento de la disciplina y el descubrimiento de la regulación y el perfeccionamiento de una anatomopolítica y el de una biopolítica" (Foucault 1999, pp. 245-246).

Anatomopolítica y biopolítica serían así -desde el punto de vista de Foucault-dos aspectos del mismo proceso, típicamente moderno, de racionalización o 'disciplinamiento' de lo vivo: en aquélla, de lo corporal-individual; en éste, de lo corporal-social, siempre con el fin de alcanzar su rentabilización política. De ahí que lo estrictamente biopolítico supone una importante alteración no solo del concepto tradicional de política sino, además, de la relación, igualmente tradicional, entre el poder político y la vida. En efecto, para Foucault, "con la época clásica [es decir, siglo XVII-XVIII], [e]l viejo derecho de vida y muerte [característico del poder soberano] se transforma a principios del siglo XIX en una tecnología de poder disciplinario, articulado en las disciplinas y en el control biológico sobre las poblaciones: se trata, ahora, de un «poder sobre la vida»" (Foucault 1999, p. 190). 
El problema biopolítico en Foucault es, en este sentido, de ocurrencia estrictamente moderna, en tanto lo vincula de modo directo al liberalismo de los siglos XVII-XVIII y el problema, paralelo, de la gubernamentalidad. Todo lo cual no quiere decir, sin embargo, que no exista, para el propio Foucault, una prehistoria de la gubernamentalidad. De hecho, Foucault se propone mostrar cómo este fenómeno fundamental en la historia de la modernidad occidental tiene su origen más remoto precisamente en esa primera forma de 'gobierno de los hombres' que habría sido la pastoral cristiana (cf. Foucault 1999, p. 197), verdadero punto de giro en la historia de Occidente; al extremo que para Foucault, en sentido estricto, antes del cristianismo no habría habido 'gobierno de los hombres' en el sentido de la 'gubernamentalidad' ni la política, en consecuencia, se habría entendido como 'pastoreo de rebaños humanos'.

\section{Del cristianismo a Platón}

La tesis según la cual solo con la irrupción del pastorado cristiano habría tenido origen la moderna biopolítica significa, por lo mismo, que ni en la antigüedad greco-romana, en general, ni en Platón y Aristóteles, en particular, existieron significativas anticipaciones estructurales de aquella forma de comprender la política que hace "entrar a la vida y sus mecanismos en el dominio de los cálculos explícitos", convirtiendo "al poder-saber en un agente de transformación de la vida humana" (Foucault 2006, p. 151). Para Foucault, por lo mismo, entre la cultura del 'cuidado de sí' de la antigüedad greco-romana pagana y la 'hermenéutica del yo' introducida por del cristianismo existe propiamente un hiato, pese a las sutiles conexiones existentes entre estas dos diversas formas de 'ocuparse de sí' que él mismo analiza en detalle (cf. Foucault 2006). De otro modo, en efecto, no resultaría comprensible el consistente recurso crítico de Foucault a esa antigüedad pre-cristiana como modelo o punto de arranque para la elaboración de una salida a la modernidad biopolítica a través del diseño de una 'estética de la existencia' y un renovado 'cuidado de la libertad' (cf, Castro 2008, pp. 375-381).

No han sido pocos los teóricos de la biopolítica, sin embargo, que -aún reconociendo la importancia de la perspectiva abierta por Foucault para el tratamiento del problema del 'ingreso de la vida en los cálculos políticos'- no han dejado de advertir las dificultades o aporías que esta hermenéutica de la modernidad política traería consigo; por no hablar de aquellos que, como Habermas (1989, pp. 180-185) o Taylor (1989, pp. 5155) la critican desde otros horizontes teóricos -acción comunicativa y comunitarismo, respectivamente- por las inconsistencias que creen descubrir en ella. Pienso, ante todo, en Agamben y Esposito, cuyas investigaciones se presentan explícitamente no solo como una prolongación de las de Foucault sino, sobre todo, como esfuerzos por superar las dificultades o cabos sueltos dejados por su interpretación de la biopolítica; en especial en lo que se refiere a la cuestión del lugar de los griegos, en general, y de Platón, en particular, en la genealogía del moderno 'gobierno de la vida'. O lo que es lo mismo, acerca del locus en el que la biopolítica encontraría su matriz. ¿Se trata, en efecto, de un fenómeno propiamente moderno, aun cuando su origen más remoto sea la pastoral 
cristiana, como piensa Foucault? ¿O será que, como piensan Agamben (2005, p. 102) y Esposito (2004, p. 50), en general y no sin ciertas oscilaciones, sería posible reconocer que ya desde Platón existiría, al menos, una orientación biopolítica del pensamiento que, por otra parte, solo en la época moderna se cristaliza? Se trata, obviamente, de una cuestión difícil de decidir, aunque pienso que son más convincentes las razones a favor de la tesis continuista (es decir, aquella que, al menos en parte, reconoce ya en Platón significativas anticipaciones estructurales de la biopolítica); y no solo porque a favor de ella se inclinarían Nietzsche y Heidegger, además de Arendt (2005, p. 250), sino, sobre todo, porque creo que una atenta lectura de Platón y de Aristóteles -aunque en el caso de este último las cosas resultan menos claras- ofrecería suficiente apoyo textual para esta alternativa. En especial, si nos fijamos en dos cuestiones bien precisas, como son el estatuto político del esclavo en Aristóteles y la vigencia de la imagen del político como pastor en Platón.

\section{Aristóteles y el problema de la esclavitud}

Según la descripción que Aristóteles nos ofrece en la Política (cf. I, capítulo 7; III, capítulos 4, 9 y 17, además de Ética nicomáquea, V, 1134a-b), la pólis es, en sentido estricto, aquella comunidad de hombres libres en vistas de la vida buena o eudaimonía, donde, por lo mismo, la política consiste en el ejercicio común y recíproco del poder con participación en las magistraturas y honores públicos. Las cosas se complican para el propio Aristóteles, sin embargo, cuando se ocupa del significado y legitimidad de la esclavitud, es decir, de la existencia de aquellos seres humanos que, estando necesariamente en la pólis ( $P$ ol. I, 4, 1254b), no forman parte de ella en sentido estricto. El argumento se articula a partir de una tesis general, de carácter universal, según la cual "mandar y obedecer no solo son cosas necesarias, sino también convenientes, y ya desde el nacimiento algunos están destinados a obedecer y otros a mandar"; para, después, ofrecer una definición del esclavo por naturaleza, al que se piensa con un estatuto ontológico-político similar al del propio cuerpo. "Cuál es la naturaleza del esclavo y cuál es su facultad resulta claro de lo expuesto; el que siendo hombre, no se pertenece por naturaleza a sí mismo, sino a otro, ese es por naturaleza esclavo. Y es hombre de otro el que, siendo hombre, es una posesión. Y la posesión es un instrumento activo y distinto" (Pol. I, 4, 1254a). Un poco antes, además, ha dicho que el esclavo es "una posesión animada" (Pol. 1253b), y un poco después, que "el esclavo es una parte del amo, una especie de parte animada separada de su cuerpo (Pol. 1255b11), que "participa de la vida de su amo" (Pol. 1260a13). Es natural, por lo mismo, que Aristóteles establezca ciertos paralelos no solo entre el esclavo y los animales domésticos ( $\mathrm{Pol}$. 1254b7) sino, sobre todo, entre el propio cuerpo y el esclavo, y donde ambos serían una 'parte instrumental' del 'amo', destinados por naturaleza (es decir, en razón de su propio bien) a ser gobernadas de un modo no-político: aquél, por el alma, éste por el amo. "El ser vivo está constituido, en primer lugar, de alma y cuerpo, de los cuales uno manda por naturaleza y el otro es mandado [...] Es posible entonces, como decimos, observar en el ser vivo el dominio señorial y el político, pues el alma ejerce sobre el 
cuerpo un dominio señorial, y la inteligencia sobre el apetito un dominio político y regio [...] En ellos resulta evidente que es conforme a la naturaleza y conveniente para el cuerpo ser regido por el alma" (Pol. 1254a-1254b).

El modelo original de la relación esclavo-amo, entonces, es el del dominio señorial (es decir, no-político) del alma sobre el cuerpo, donde el esclavo es integrante de la pólis pero bajo la modalidad de ser un 'cuerpo-instrumento' que se 'rige'. "Así, pues, todos los seres que se diferencian de los demás como el alma del cuerpo y como el hombre del animal (se encuentran en esta relación todos cuantos su trabajo es el uso del cuerpo, y esto es lo mejor de ellos), estos son esclavos por naturaleza, para los cuales es mejor estar sometidos a esta clase de mando, como en los casos mencionados" (Pol. 1254b8). Al interior de la pólis aristotélica, en este sentido, existe una presencia 'humana'-la del esclavo, que es, desde este punto de vista, 'fuerza de trabajo corporal' y nada más- sobre la que no cabe un gobierno político - similarmente a lo que sucede con los propios cuerpos y los animales domésticos- sino solo un dominio señorial.

Es cierto, entonces que, aunque desde el punto de vista de la definición inicial de pólis y de política, en Aristóteles no habría un 'gobierno de los hombres' en el sentido de la 'gubernamentalidad' foucaultiana (precisamente porque los 'hombres' aquí considerados son los ciudadanos libres e iguales), resulta evidente que la propia estructura de la pólis supone la presencia de hombres que, aun cuando participan en general de la naturaleza humana (definida sobre todo por la presencia del alma racional) no son enteramente humanos al modo en que sí lo es la mujer y el niño (que aunque inferiores al hombre libre son plenamente humanos); es decir, para decirlo con el propio Foucault (cf. Foucault 2005, pp. 141-142), la misma estructura de la pólis exige la presencia de hombres a los que la disciplina de 'gobierno' está interesada en hacer económicamente útiles aunque dóciles desde el punto de vista político. Para Aristóteles, en efecto, el esclavo "participa de la razón tanto como para percibirla, aunque no para poseerla" (1254b9), de modo que, al igual que en el caso de la mujer y del niño, en él existen las partes del alma, aunque de diferente manera: en efecto, "el esclavo no tiene en absoluto la facultad deliberativa; la mujer la tiene, pero sin autoridad [o falta de seguridad]; y el niño la tiene, pero imperfecta" (Pol. 1260a7). El esclavo, en este sentido, posee un estatuto especialmente ambiguo, similar al que ocupa el propio cuerpo; pues no es ni mucho menos una simple 'cosa' (es decir, un instrumento inanimado, a la manera en que lo es el arado) sino que representaría la presencia de lo semejante/ desemejante al interior de la pólis, cuya característica fundamental es la de ser visto como fuerza-de-trabajo o un cuerpo-vivo cuya vida, al no serle propia (pues 'participa de la vida de su amo'), está disponible para su uso. En este sentido, podemos decir que en Aristóteles el problema político que representan los cuerpos es el mismo que representan los esclavos: no hay ciudad sin cuerpos ni sin esclavos, pero ni el cuerpo ni el esclavo son 'ciudadanos'; para ambos, por lo mismo, habrá que buscar un modo de dependencia -es decir, una forma de gobierno- acorde con su estatuto ontológico, que, pese a todo, no se traduce en una forma de pro-ducción en el sentido de la poiesis. Pues como dice el propio Aristóteles (Pol. 1258a10), "la política no produce a los hombres, sino que los recibe de la naturaleza y se sirve de ellos". 


\section{Platón. De la República al Político}

Aquello que en Aristóteles no se habría verificado sí sucedería, en cambio, en Platón y su manera de entender la política como técnica poiética, en cuyos Diálogos la figura del pastor ocupa un lugar central. Al punto que se podría afirmar que con Platón la política se muestra, por primera vez aunque de un modo decisivo, como una "tarea zoopolítica", es decir, como aquella "antropotécnica política cuyo objetivo no es solo dirigir por el camino de la mansedumbre a un rebaño ya manso de por sí, sino emprender una nueva crianza sistemática de ejemplares humanos más próximos al arquetipo" (Sloterdijk 2003, pp. 75-77), según se puede apreciar, sobre todo, en la República y el Político.

A. En la República, en efecto, Platón se propone ofrecer -prolongando lo ya señalado en el Gorgias - una respuesta definitiva al problema de la justicia tal como venía plateándose, sobre todo, en la figura de los portavoces oficiales de la 'ley natural' del más fuerte, a saber, los sofistas. Solo que esta defensa de la virtud de la justicia, y de la necesidad de un pólis bien ordenada, no consiste, como se podría pensar, ante todo en oponer al 'realismo' propio de los sofistas un 'idealismo' moralizante. Más bien sucede lo inverso. Pues frente a la teoría sofística de la felicidad como desenfreno (del que el tirano elogiado por Trasímaco sería el caso más extremo y perfecto) y de la justicia como expresión de la simple impotencia de los débiles, Platón defiende la idea de la 'felicidad' como 'justicia' y 'orden' elaborando para ello una teoría política -de la vigilancia de sí y de los otros, y de la necesidad del castigo- en la que el político perfecto (cf. Rep. I, 343a-345e; III, 461a-b; IV, 440d) se gobierna a sí mismo y a los demás al modo en que el pastor gobierna a su rebaño (y, por lo mismo, en antítesis a la figura del tirano, cuya vida es la más desgraciada pues se ve obligado a gobernar a otros sin gobernarse a sí mismo (cf. Rep. IX, 579c-d). De ahí que, contrariamente a lo que se pueda pensar, Platón rechaza a los sofistas no porque éstos apelen, por ejemplo, a la violencia y a la mentira -pues Platón mismo piensa que es legítimo su uso, en determinados casos al menos, por parte del político que es filósofo (cf. Rep. 382c-d y 389b-c)- sino porque el fin de la sofística no es otro que la anarquía y el desorden de sí. Que es justamente lo que, según Platón, inhabilita a los hombres para el ejercicio de la genuina política en tanto "praxis orientada al cuidado de esos vivientes que son los hombres" (Gorgias 516b).

De ahí la necesidad de ser especialmente cuidadoso en el desciframiento del discurso platónico. Pues tras el elogio sofístico del desenfreno hedonista se ocultaría un debilitamiento de las fuerzas vitales, imprescindibles para el autogobierno y el consecuente gobierno sobre otros, y que Platón no solo desenmascara como la verdadera impotencia sino que combate, proponiendo la imagen del político perfecto como aquel único 'buen pastor' que, como guardián perfecto de los demás pero ante todo de sí mismo (Rep. III, 413e), posee de modo exclusivo aquella 'ciencia de la vigilancia' que es la única que está en condiciones de hacer buenos y felices a los hombres (cf. Rep. IV, 421a, 428d). Que es justamente lo que explica la necesidad de educar correctamente a los futuros políticos-guardianes, que como "los mejores artesanos de su propia función" (Rep. 421c) deben llegar a ser aquellos pastores que, auxiliados por perros guardianes, cuiden celosamente (en el doble sentido de 'con detalle' y 'con atención' o 'de modo 
vigilante') del bienestar de sus ovejas (cf. Rep. III, 416a y IV, 440d). Pues son ellos los únicos capaces de hacer felices a los hombres, tanto en lo privado como en lo público (cf. Rep. V, 473d).

Es absolutamente decisivo, en este sentido, el proceso formativo al que deben ser sometidos los futuros políticos-pastores, que no solo incluye la gimnasia y la música sino que, por sobre todo, la dialéctica. Hay que tener bien presente, sin embargo, que el 'símil de la caverna' describe plásticamente un proceso formativo -completamente atravesado por el dolor de quien es arrastrado fuera de la caverna y de quien es arrastrado dentro de ella- que culmina, no con la contemplación extática del Bien por parte del filósofo sino con su retorno forzado a las profundidades de la caverna. La paideia platónica comienza en la caverna y allí encuentra su término (télos), de modo que la racionalidad extática de la contemplación pura se ve sobrepasada por una 'racionalidad política', en la que el filósofo busca aplicar, al interior de la caverna, el modelo visto fuera de ella.

Es en este contexto donde deben inscribirse, por lo mismo, los anti-tipos del 'buen gobernante' y del 'tirano' tal como son descritos en la República, y que al inicio del diálogo fueron representados con las imágenes del 'pastor verdadero' y el 'pastor falso'; y cuya diferencia de fondo radica en que el buen gobernante es aquel 'pastor' en quien, vigilando cuidadosamente sus ovejas, predomina la racionalidad-que-calcula, mientras que en el tirano predomina el éros, que es, él mismo, tirano (cf. Rep. 573b). Así, lo descrito sobre los diversos regímenes políticos (en especial en el libro VIII) culmina en la descripción del tirano (y del poeta imitativo) como anti-tipo del pastor genuino. "Pues un hombre llega a ser perfectamente tiránico cuando, por naturaleza o por hábitos o por ambas cosas a la vez, se torna borracho, erótico o lunático" (Rep. 573c); es decir, cuando habita dentro de sí, gobernándolo, el Eros tirano, que "conduce a todos los demás deseos como a sus custodios" (Rep. 573e). Pues lo que más se aleja de la razón, de la ley y del orden, precisamente "son los apetitos eróticos y tiránicos" (Rep. 587b). Mientras que en el caso del hombre destinado al poder político, lo que rige su vida es "obra del elemento calculador que existe en nuestra alma" (Rep. 602e). La razón (phrónesis) que nos aproxima a la verdad es, en este sentido, el lógos que “confía en la medición y el cálculo" (Rep. 602e-603a). De ahí que, por oposición a la forma erótica de la razón tiránica, la forma propia de la razón pastoral del filósoforey sea la logística, cuyas consecuencias o efectos en el terreno del 'gobierno de los hombres' son decisivas.

En lo inmediato, Platón propone una legislación en la que dos de las técnicas más importantes de la ciudad - medicina y justicia- solo se ocupen de los ciudadanos bien constituidos. "En cuanto a los otros, se dejará morir a aquellos otros que estén mal constituidos físicamente; y a los que tengan un alma perversa por naturaleza e incurable se los condenará a muerte" (Rep. 409e-410a). Platón tiene en mente el caso de Asclepio, quien habría ideado el arte de la medicina para aquellos que, aunque afectados por alguna enfermedad bien delimitada, mantienen sus cuerpos sanos "gracias a la naturaleza y a su régimen de vida"; en cambio, "a fin de no perjudicar los asuntos políticos [...] en los casos en que los cuerpos están totalmente enfermos por dentro, no intentó prolongar la desdichada vida de los enfermos por medio de dietas [...] ni 
hacerles procrear hijos semejantes a ellos, probablemente. Ha pensado, en efecto, que no se debía curar al que no puede vivir en un período establecido como regular, pues eso no sería provechoso para él ni para la pólis" (Rep. 407c-e). El criterio que rige la praxis médica, en este sentido, es el de la utilidad de quien está, en el fondo, en condiciones de cumplir bien "el trabajo que le corresponde", de modo que el ideal del ciudadano es el del trabajador productivo (Rep. 406c). De ahí que, en perfecta lógica, deban ser cuidadosamente vigilados los procesos reproductivos de la población en general y la de los guardianes en particular, quienes, una vez pasada la edad correcta de procrear, podrán unirse libremente a quienes quieran (excepto con su madre/padre, hermana/ hermano, hija/hijo), "no sin antes exhortarlos a poner gran celo en que nada de lo que hayan concebido, si así ha sucedido, vea la luz, y, si escapa a sus precauciones, plantearse que semejante niño no será alimentado" (Rep. 461b-c). A la eutanasia viene a agregarse, en este sentido, el aborto y el infanticidio como parte de una política reproductiva (atenta a la aptitud de los miembros de la pólis para el trabajo productivo), en la que el criterio decisivo es el de la rentabilidad social de los futuros 'trabajadores' (que solo son 'felices', además, si cumplen con eficiencia con la propia función). Es interesante, en este sentido que, puesto Platón en la necesidad de ofrecer una explicación acerca de la ocurrencia de la corrupción en la pólis ideal, indique, como causa principal, la inhabilidad de los guardianes para vigilar con suficiente atención -es decir, "por medio del cálculo acompañado de percepción sensible"- a las uniones sexuales que en ella tienen lugar (Rep. 546a y siguientes).

Los políticos-pastores, así, deben vigilar los procesos reproductivos, eliminando, o expulsando fuera de la pólis (Rep. 540e-541a) a quienes se muestren no-educables según los principios de su paideia política, y por lo mismo, no susceptibles de formar parte (ni aún bajo la forma de una simple mano-de-obra) de una comunidad política a la que se quiere, aún en su multiplicidad, básicamente homogénea (Rep. 462a-c). Los miembros de la pólis ideal platónica, en efecto, deben sentirse -en virtud de una de esa 'mentiras nobles' (Rep. 414c) que, bajo la forma de un 'mito' político, resultan imprescindibles en el proyecto de Platón- como "hermanos y como hijos de la misma tierra", pese a sus diversas funciones y la necesaria jerarquía que ello implica (Rep. 414e y 415a), en contraste con aquellos otros -es decir, los bárbaros- a los que es legítimo no solo hacer la guerra sino, en último término, exterminar (Rep. 471a).

La pregunta fundamental para Platón es, por lo tanto, cómo hacer para que, "todos, sometidos bajo el mismo gobierno, seamos en lo posible semejantes y amigos" (Rep. 590d). Ya hemos visto algunas de las medidas ideadas por Platón para la consecución de este fin. Todas ellas, sin embargo, parten de un supuesto que explica la necesidad de una educación diferenciada: los hombres no son iguales por naturaleza, en el sentido que en ellos los tres elementos en los que se divide el alma (racional, irascible, concupiscible) no están presentes de igual modo; que es lo que explica las diferentes funciones que cada uno de ellos debe cumplir al interior de la pólis y, por lo mismo, el papel de la justicia como virtud política fundamental. Y no siendo iguales, no todos están en condiciones de gobernarse a sí mismos en sentido propio. El que todos los habitantes de la pólis deban ser virtuosos, por lo tanto, no contradice la idea del necesario gobierno de unos sobre otros, pues se trata de dos tesis perfectamente compatibles. 
Pues aquellos hombres en quienes predomina la parte concupiscible no solo deben, para ser fieles a su propia naturaleza, ocuparse de los trabajos más indignos de la pólis (en general, trabajos manuales y comercio, para lo cual necesitan adquirir las virtudes apropiadas para ello) sino que, además, deben ser educados para soportar dócilmente el gobierno que sobre ellos deben ejercer -en fidelidad a su propia naturaleza, y no por gusto personal-aquellos en quienes predomina la parte racional, que, a su vez, se sirven de aquellos otros en quienes predomina la parte irascible (y que, como cualquiera de los otros tipos humanos, deben cultivar las virtudes apropiadas para ello). Es decir, ni todos los hombres son iguales ni todos deben cultivar las mismas virtudes: pues los mejores deben adquirir las virtudes que habilitan para el mando, los peores las virtudes que habilitan para la obediencia. Con lo cual, al interior de la pólis ideal, se reintroduce (aunque reinterpretado) el esquema amo-esclavo que aparentemente había quedado fuera. Para Platón, en efecto, la clase obrera y el artesanado, incapaz de gobernar a las bestias que llevan dentro, debe ser esclava del hombre mejor; aunque esto, advierte Platón, "no porque pensemos que el esclavo debe ser gobernado para su daño, como creía Trasímaco de los sometidos a su gobierno, sino porque es mejor para todo ser el estar sujeto a lo divino y racional, sobre todo conteniéndolo en su interior como propio, pero si no, dándole órdenes desde fuera" (Rep. 590d). En este sentido, el conocido esquema tripartito de la pólis platónica, en correspondencia con el esquema tripartito del alma, no solo supone una división clara entre sus habitantes sino, sobre todo, una férrea subordinación política de unos a otros, en la que 'los más' son conceptualizados como esclavos de 'los menos'; es decir-según la caracterización habitual del esclavocomo 'instrumentos' en manos de los sabios modeladores de la pólis. Con lo cual, en cierto sentido, la metáfora del pastor resulta sobrepasada, en tanto la relación política fundamental entre los miembros de la misma pólis no es tanto la del pastor que cuida a sus ovejas sino la de quien gobierna o controla instrumentos; y donde, por lo tanto, el principio de la soberanía es llevado a sus posibilidades extremas. Pues la diferencia entre gobernar seres vivos (el gobierno pastoral) y gobernar instrumentos (el gobierno político sobre esclavos) radica, ante todo, en que aquéllos poseen una naturaleza que, aunque moldeable, viene dada, y a la que el pastor debe, en principio, acomodarse; en los instrumentos, en cambio, hasta su propia naturaleza vienen pro-puesta según los fines del artesano que los pro-duce. De modo que solo en esta última identificación del pastor con el amo la soberanía del productor es absoluta -aunque, claro está, no arbitraria- en el sentido de no estar sujeto a normas que restrinjan su capacidad de acción. Al punto que al gobernante sabio -como se afirma en el Político, del que nos ocuparemos a continuación- le estará permitido gobernar "conforme a leyes o sin leyes, con el consentimiento de los gobernados o por imposición forzada", de modo que si "mandan a la muerte o destierran a algunos individuos para purificar y sanear la ciudad, o si envían aquí o allá colonias como si fueran enjambres de abejas para reducir la ciudad o, por el contrario, traen inmigrantes de algún otro lado para aumentar su volumen, mientras procedan con ciencia y justicia para salvarla e introduzcan en lo posible mejoras, debemos decir que este régimen político es el único recto" (Rep. 293d).

Parece ser cierto, entonces, que el arte del gobierno de los hombres, en Platón, se configura exactamente como zoopolítica antropotécnica (Sloterdijk 2003, p. 75), en 
la que los seres humanos son gobernados precisamente porque son pro-ducidos por el político-pastor que, en definitiva, asume los rasgos del soberano absoluto. De ahí que no sea nada casual la centralidad que en la República ocupa el tema de la poiesis, pues el fondo de la discusión de Sócrates y sus interlocutores parece no ser otro que el de la relación entre política y arte. O más exactamente, el de la cuestión de en qué sentido la política no solo es un arte, en el sentido de téchne, sino, sobre todo, arte en el sentido más originario de poeisis. Pues no se trata solo de la afirmación, más inmediata, según la cual el arte (la poesía tradicional, Homero en especial) debe someterse a las exigencias de la paideia política sino, sobre todo, de hasta qué punto se comprende que la téchne politiké es poiesis en el sentido de pro-ducción. Así, habría que leer la República (y su concepto, radicalizado, de la política como arte del pastoreo) a la luz de lo que se dice en el Simposio, cuando se define a la poiesis como "todo lo que es causa de que algo, sea lo que sea, pase del no-ser al ser [...] de suerte que todas las actividades que entran en la esfera de todas las artes son creaciones y los artesanos de éstas, creadores" (Simp. 205b). De modo que no solo la política debería entenderse como 'creación', y el político como un 'creador', que hace 'ser' a los hombres (en el sentido de salira-la-presencia) en tanto les asigna una forma y función (la propia de cada cual) sino, sobre todo, que la expulsión de la poesía de la pólis ideal es la expulsión de la poesía corrupta - a la que Platón llama poesía imitativa- y su reemplazo por la más alta forma de 'poesía' que es la política perfecta. Y a la que, en su condición de poiesis le estaría permitido un amplio recurso a la mentira y el engaño, como claramente afirma Platón en numerosos pasajes de la República. Por ejemplo, allí donde se afirma que, tal como los médicos en relación con ciertas drogas, "si hay pues alguien a quien le sea lícito faltar a la verdad, serán los gobernantes de la pólis, que podrán mentir con respecto a sus enemigos o conciudadanos en beneficio de la comunidad, sin que ninguna otra persona esté autorizada a hacerlo" (Rep. 389b). De ahí que "de la mentira y el engaño es posible que hayan de usar muchas veces nuestros gobernantes por el bien de sus gobernados", como es propio de quien es "audaz" (Rep. 459c). Las tareas que se impone a la política, en tanto poiesis, exige, por lo mismo, un creador audaz, capaz de ir más allá de los límites de lo habitual.

B. Que es, precisamente, una de las cuestiones más importantes tratadas en el Político. En el centro de este Diálogo, en efecto, está el viejo problema (ampliamente tratado en el Fedro y la Carta VII) de la superioridad de la oralidad por sobre la escritura, aunque ahora bajo la forma de la relación de (in)dependencia del saber del político perfecto respecto de la ley. El problema a la luz del cual, sin embargo, debe examinarse esta decisiva cuestión es la de si aún en este Diálogo, y hasta qué punto, Platón confirma la caracterización del político como 'pastor' y de la política como 'pastoreo de rebaños humanos' ofrecida en la República. Tampoco en este caso se trata de un asunto sencillo, aunque creo que hay razones para pensar que, en lo esencial, Platón sigue pensando al político y a la política en los términos en los que lo venía haciendo hasta ahora. Es decir, creo que hay razones suficientes para pensar que aún cuando en el Político se prefiere caracterizar al político con la imagen del tejedor, y ya no con la del pastor, en lo esencial, ese cambio confirma los rasgos fundamentales de la política como téchne poiética presente en la República. 
En la primera parte de la sección dedicada a esta cuestión, en cualquier caso, Platón insiste en vincular al político con la imagen del pastor, al punto que se lo entiende, en general, como 'aquel que cría los rebaños humanos'. Se afirma, en este sentido, que parecería correcto definir a la política como aquel "cuidado de la comunidad humana en su conjunto y un arte de gobierno que se ejerce sobre todos los hombres" (Polit. 276c), a la que además se la califica como el 'arte de ocuparse del rebaño de animales bípedos que lo aceptan voluntariamente" (Polít. 276e). A diferencia de lo que sucedía en la República, sin embargo, esta definición ahora resulta demasiado genérica para los presentes propósitos dialécticos de Platón, pues ahora advierte que son muchos de quienes se podría predicar ese mismo "cuidado relativo a las ciudades" (Polít. 279a). La analogía del político con el pastor parece no ofrecer la precisión que se busca; de ahí la necesidad de recurrir a un modelo que "nos permita descubrir de un modo adecuado el objeto de nuestra búsqueda", que sí parece ofrecer la imagen del tejedor; y más específicamente, el tejedor de lana (Polit. 279b), en la que se entrelaza la trama y la urdimbre, es decir, como se verá más tarde, lo suave y lo firme (Polit. 283b). La evidente consecuencia inmediata de todo esto -a través del excursus dedicado al 'término medio' y la distinción entre 'concausas' y 'causas'- es que "al rey se lo ha puesto ya aparte de las múltiples artes afines y particularmente de todas aquellas que tienen que ver con los rebaños" (Polit. 287b). En particular, importa la diferencia entre concausas y causas, pues ello permite diferenciar al político en sentido propio de todos aquellos técnicos que hacen posible el ejercicio de la soberanía pero que no son, ellos mismos, soberanos. Tras todo lo cual se llega a la conclusión -ya afirmada antes, en 258 b - de que la política es una "ciencia crítica y prescriptiva (antes se había hablado de 'ciencia directiva', en 260c, que significa en este caso lo mismo) referida a seres vivos" (Polit. 292c); más específicamente, como aquella "ciencia del gobierno ejercido sobre los hombres" (Polit. 292c). Tal 'gobierno de los hombres', sin embargo, posee las características propias del tiempo (eón) en que vivimos (es decir, aquel tiempo posterior al gobierno de Cronos, cuando solo gobiernan 'hombres normales' y prima la escritura por sobre la oralidad); en efecto, aún el mejor de los políticos actuales-que es solo un igual entre iguales- es aquel que gobierna a todas las demás artes presentes en la pólis sometiéndose a las leyes y, de ese modo, es capaz de entretejer a todas las artes y a todos los ciudadanos del modo más correcto posible (Polít. 305e). El político-tejedor, en efecto, es uno que no solo no gobierna directamente a los hombres -pues lo hace a través de las demás artes o técnicas- sino, sobre todo, que gobierna sometiéndose, él mismo, a la soberanía de la ley (a través de la cual solo se puede prescribir lo bueno en términos generales, sin contemplar nunca los casos particulares); de ahí que este tipo de político - cuya soberanía está doblemente mediada - no sea capaz de darle a cada cual lo mejor, absolutamente hablando, de modo directo (Polit. 295a).

Así y todo, a este político-tejedor se le atribuyen amplias facultades; en efecto, es una forma de 'gobierno de los hombres' que no solo "conoce el punto de partida y la puesta en marcha, en lo que toca a la oportunidad y la inoportunidad, de los más importantes asuntos de la ciudad" sino, sobre todo, cuyo 'entretejer' tiene por función primordial tomar a su cuidado el "conjunto de lo que contribuye o atañe a la vida" (Polít. 307e). El político-tejedor de Platón, en este sentido, no solo se ocupa de entretejer los 
diversos caracteres humanos a fin de dar forma a las distintas 'formas de vida' (bíos) sino, antes de eso, es aquel que gobierna la 'vida-desnuda' (zoé) de los habitantes de la pólis; pues solo a partir de este presupuesto resulta comprensible que a este político se le atribuya la facultad de eliminar con la muerte, el exilio o la esclavitud a quienes se muestren incapaces de participar de la excelencia (Rep. 308e y 410a), en tanto sí se le permite someter a quienes se muestren aptos para ser educados en la virtud a una serie de dispositivos orientados a asegurar su propia felicidad (ante todo, el matrimonio y la procreación, racionalmente calculados) (Rep. 545d).

Toda esta comprensión del político-tejedor, adecuada a las posibilidades de la época actual, sin embargo, no le impide a Platón seguir pensando que el político perfecto tiene como modelo propio no al tejedor sino al gobierno pastoral de la época de Cronos. Lo del tejedor, en este sentido, aparece solo como un sucedáneo epocal respecto de aquel otro político -aún existente, pero que debe servir de medida o regla a todas las demás formas de gobierno- que ya no es más 'un igual entre iguales' sino que, como el pastor respecto de las ovejas, es tan "superior en cuerpo y alma" a los demás hombres (Polit. 301e) que parece un dios entre ellos (Polit. 303b y 309c; vid., además, Aristóteles, Política 1284a). Al punto que este político perfecto no se limitaría a redactar leyes, a las que quedaría sometida su soberanía, ni gobernaría indirectamente a través de otros, sino que su propio saber sería la única ley que regiría su directo y siempre exacto 'gobierno de los hombres' (Polit. 293a-294b; 301c-d) a través del cual sí sería capaz de prescribir a cada cual lo conveniente; de modo que la legitimidad del régimen perfecto no procede de una legalidad preestablecida (ni, mucho menos, del asentimiento de los gobernados) sino de la persona misma de este soberano extraordinario -cuya aparición Platón cree que habría que favorecer (Polit. 301e)- en virtud de cuyo saber se constituiría en la única y suprema 'norma viviente' (Polít . 297a).

\section{Consideraciones finales}

De la República al Político, en consecuencia, no solo se conserva la imagen del políticopastor y la comprensión de la política como 'pastorado de rebaños humanos' sino que, incluso, hasta cierto punto se habría radicalizado. En este sentido, no se podría afirmar ni que la imagen del pastorado ocupa solo un lugar secundario en la República ni que el Político ofrecería "la recusación en debida forma del tema del pastorado"; como tampoco, por lo mismo, que "la verdadera historia del pastorado como núcleo de un tipo específico de poder sobre los hombres, su historia en el mundo occidental como modelo, como matriz de procedimiento de gobierno de los hombres, recién comienza con el cristianismo" (Foucault 2006, p. 176).

Parecen ampliamente justificadas, desde este punto de vista, las observaciones críticas que se han formulado a la genealogía foucaultiana de la biopolítica, no tanto porque se pretenda que ya en Platón mismo se habría configurado de un modo explícito una forma de 'política sobre la vida', orientada a su control y explotación total-como parece creer Agamben cuando afirma que "la política occidental es, al mismo tiempo 
y desde el origen biopolítica" (Agamben 2005, p. 102)- sino, simplemente, porque parece innegable que ya en la República y el Político habría habido, al menos, "una orientación biopolítica del pensamiento" (Esposito 2004, p. 50). En qué sentido la categoría de inmunitas introducida por Esposito podría constituirse en aquello que, faltando en Platón, haría del moderno 'gobierno de la vida' una biopolítica en sentido propio es algo que habría que examinar con detalle (Esposito 2004, p. 51). En cualquier caso, es evidente que nuestra actual comprensión del fenómeno de la biopolítica se vería afectada, en menor o mayor grado, si admitimos que no es el modelo del pastorado cristiano la matriz de la que arranca el moderno 'gobierno de la vida' sino la zoopolítica antropotécnica presente en Platón; pues en tal caso tendríamos que reconocer, quizás, no solo la tesis según la cual lo que hay de pastorado en el cristianismo no sea sino una parte de la herencia griega con la que carga, pero que podría no serle esencial (cf. Henry 2001) sino, sobre todo, que lo greco-romano, como lugar desde donde Foucault pretende arrancar una nueva 'estética de la existencia', sea precisamente lo que nos impide transitar desde una política sobre la vida a una política de la vida.

\section{Referencias bibliográficas}

Agamben, G. (2004), Estado de excepción. Buenos Aires: Adriana Hidalgo editores. Traducción de Flavia Costa e Ivana Costa.

(2005), Lo abierto. El hombre y el animal. Valencia: Pre-textos. Traducción de Antonio Gimeno Cusperina.

(2006), Homo sacer. El poder soberano y la nuda vida. Traducción de Antonio Gimeno Cusperina. Valencia: Pre-textos.

Arendt, H. (2005), La condición humana. Traducción de Ramón Gil Novales. Barcelona: Paidós.

Aristóteles. (2001), Política. Traducción de Manuela García Valdés. Madrid: Gredos. (1998), Ética a Nicómaco. Traducción de Julio Pallí Bonet. Madrid: Gredos.

Castro, R. (2008), Foucault y el cuidado de la libertad. Ética para un rostro de arena. Santiago de Chile: LOM.

Esposito, R. (2004), Bíos. Biopolitica e filosofia. Milano: Enaudi.

Foucault, M. (1999), Escritos esenciales. Estética, ética, hermenéutica. Barcelona: Paidós. Traducción de Miguel Morey.

(2005), Seguridad, territorio y población. Traducción de Horacio Pons. Buenos Aires: FCE.

(2006), Historia de la sexualidad. La voluntad de saber. Traducción de Ulises Guiñazú. Madrid: Siglo XXI.

Habermas, J. (1989), El discurso filosófico de la modernidad. Traducción de Manuel Jiménez Redondo. Buenos Aires: Katz. 
Heidegger, M. (2000), "Carta sobre el humanismo", en Hitos. Madrid: Alianza. Traducción de Helena Cortés y Arturo Leyte.

Henry, M. (2001), Yo soy la verdad. Para una filosofía del cristianismo. Traducción de Javier Teira Lafuente. Salamanca: Sígueme.

Jonas, H. (2008), El principio de responsabilidad. Traducción de Javier Fernández Retenaga. Barcelona: Herder.

Platón (2000), República, en Diálogos, vol. IV. Traducción de Conrado Eggers Lan. Madrid: Gredos.

(2005), Político, en Diálogos, vol. V. Traducción de María Isabel Santa Cruz. Madrid: Gredos.

(2003), Simposio, en Diálogos, vol. III. Traducción de Miguel Martínez Hernández. Madrid: Gredos.

Sloterdijk, P. (2003), Normas para el parque humano. Traducción de Teresa Rocha Barco. Madrid: Siruela.

Taylor, C. (1989), "Foucault, la Liberté, la Verité”, en Michel Foucault. Lectures Critiques. Bruxelles: Éditions Universitaires; pp 54-68. 